\title{
LRAT Overexpression Diminishes Intracellular Levels of Biologically Active Retinoids and Reduces Retinoid Antitumor Efficacy in the Murine Melanoma B16F10 Cell Line
}

\author{
Philipp M. Amann ${ }^{a}$ Katharina Czaja ${ }^{a}$ Alexandr V. Bazhin ${ }^{b}$ Ralph Rühld \\ Stefan B. Eichmüller ${ }^{c}$ Hans F. Merk ${ }^{a}$ Jens M. Baron ${ }^{a}$ \\ ${ }^{a}$ Department of Dermatology and Allergology, RWTH Aachen University, Aachen, ${ }^{\mathrm{b}}$ Department of General, Visceral \\ and Transplant Surgery, Ludwig-Maximilian University Munich, Munich, and ' Division of Translational Immunology, \\ German Cancer Research Center, Heidelberg, Germany; ${ }^{d}$ Department of Biochemistry and Molecular Biology, \\ University of Debrecen, Debrecen, Hungary
}

\section{Key Words}

Melanoma $\cdot$ Retinoids . Retinoid resistance .

Retinoid sensitivity · Vitamin A metabolism

\begin{abstract}
Background/Aim: Vitamin A (all-trans-retinol, ATRol) serves as a precursor for all-trans-retinoic acid (ATRA), a ligand for the retinoic acid receptor (RAR), representing a potent regulator for many physiological processes. While murine melanoma cells are highly sensitive to retinoid treatment, human melanoma cells have developed still unidentified mechanisms that mediate cellular retinoid resistance. One of the key retinoid metabolizing enzymes is lecithin retinol acyltransferase (LRAT), which catalyzes the transformation of ATRol into inactive retinyl esters. LRAT is highly expressed in human melanoma cells. The aim of this study was to identify the mechanisms in retinol metabolism that are responsible for cellular retinoid sensitivity in the murine melanoma cell line B16F10. Methods: mRNA expression analysis, cell viability assessment and determination of intracellular retinoid levels using HPLC analysis of a generated LRAT-overexpress-
\end{abstract}

ing B16F10 cell line compared to the control B16F10 cell line. Results: We found that the murine retinoid-sensitive B16F10 cell line does not express the enzyme LRAT. LRAT overexpression decreased the antiproliferative effects of retinoid treatment in these melanoma cells. The RAR-regulated enzyme Cyp26a1 showed a significantly lower expression in LRAT-overexpressing B16F10 cells. Cyp26a1 expression was restored after ATRA incubation. HPLC analysis revealed that the level of inactive retinyl ester increased after ATRol treatment, and levels of the substrate ATRol and biologically active ATRA significantly decreased in LRAT-overexpressing murine melanoma. Consistently with this, levels of 4-oxoretinoic acid, an ATRA metabolite and Cyp26a1 product, were also decreased in LRAT-overexpressing cells. Conclusion: Our results revealed a direct link between LRAT expression and regulation of ATRA levels indicating that the absence of LRAT-catalyzed retinol esterification is important for mediating retinoid sensitivity in murine melanoma cells. Thus, our data suggest that LRAT overexpression represents a novel mechanism by which tumor cells can escape high supplementary ATRA levels that mediate tumor-suppressive RAR signaling.

(c) 2015 S. Karger AG, Basel

\section{KARGER 125}

(c) 2015 S. Karger AG, Base

$1660-5527 / 15 / 0284-0205 \$ 39.50 / 0$

E-Mail karger@karger.com

www.karger.com/spp
Dr. Philipp Amann

Department of Dermatology and Allergology

University Hospital, RWTH Aachen University

Pauwelsstrasse 30, DE-52074 Aachen (Germany)

E-Mail pamann@ukaachen.de 


\section{Introduction}

Vitamin A derivatives (retinoids), like all-trans-retinoic acid (ATRA), are essential for many physiologically relevant processes like cell growth and differentiation during embryogenesis and in the adult organism, and are also important for skin physiology [1-4]. At the molecular level, ATRA binds and activates the retinoic acid receptors (RARs), which directly regulate the transcription of various target genes [1]. Intracellular retinoid levels are regulated by mechanisms that are not completely understood $[5,6]$. For ATRA synthesis, vitamin A (all-trans-retinol, ATRol) can be oxidated via all-trans-retinal (ATRal) as a metabolic intermediate $[7,8]$. Due to the antiproliferative and prodifferentiation effects of ATRA [9], it is successfully used to treat several types of cancers $[10,11]$. However, many human melanoma cell lines are highly resistant to ATRA treatments $[12,13]$, and ATRA and its isomer 13-cis-retinoic acid are poor therapeutics for human melanoma [14-17].

The lack of information about the mechanism of ATRA resistance in human melanoma cells greatly hampers efforts to improve clinical protocols that use this drug. Recently, efforts have been made to identify these tumor-specific mechanisms of retinoid resistance and metabolic response in melanoma cells $[18,19]$. Aberrant vitamin A metabolism is an attribute of cancer cells presenting such a potential retinoid resistance mechanism. It was shown that cancer-specific modulations in retinoid metabolism reduce ATRA levels in cancer cells and that both the synthesis and metabolism of the bioactive metabolites of retinol are impaired in cancer cells relative to normal cells $[10,11]$. Recently, we identified alterations in retinoid metabolism in human melanoma cells $[6,20]$. ATRol can be oxidized to ATRA or alternatively be esterified into biologically inactive retinyl esters. This key metabolic step is catalyzed by the enzyme lecithin retinol acyltransferase (LRAT) [21]. We showed that LRAT expression is highly upregulated in human melanoma cells as compared to benign melanocytes [20]. We believe that LRAT may be important for the removal of ATRol which is the precursor for ATRal and ATRA production.

Importantly, in contrast to human melanoma, many studies showed that murine melanoma cell lines, such as $\mathrm{B} 16 \mathrm{~F} 10$, are highly sensitive to retinoids both in vitro and in vivo, and that retinoids exhibit significant effects on cell differentiation, proliferation, invasion and metastasis formation [22-31]. The purpose of this study was to identify the mechanisms in retinol metabolism that can be responsible for cellular retinoid sensitivity in the murine melanoma cell line B16F10.

\section{Materials and Methods}

\section{Cell Culture and Reagents}

The murine melanoma $\mathrm{B} 16 \mathrm{~F} 10$ cell line was cultivated at $37^{\circ} \mathrm{C}$ in an atmosphere of $5 \% \mathrm{CO}_{2}$ in RPMI 1640 with $2 \mathrm{mM} \mathrm{L}$-glutamine (Gibco/Invitrogen, Darmstadt, Germany), supplemented with $10 \%$ fetal calf serum (Biochrom, Berlin, Germany). ATRol, ATRal and ATRA were purchased from Sigma (Taufkirchen, Germany).

\section{LRAT Overexpression}

Plasmid amplification was performed in Escherichia coli using mouse LRAT cDNA plasmid (MR225686, Origene, Rockville, Md., USA) or pEntry (PS100001, Origene) as the control according to the manufacturer's protocol.

Plasmid DNA from bacterial lysates was purified using the HiSpeed Plasmid Maxi Kit (Qiagen, Hilden, Germany).

B16F10 melanoma cells were plated $8 \mathrm{~h}$ before transfection at $70 \%$ confluency. DNA transfections were performed using the XtremeGENE 9 DNA Transfection Reagent (Roche, Penzberg, Germany) according to the manufacturer's recommendations. The chosen ratio of transfection reagent:DNA was 6:2. After transfection, selection was made by adding $2 \mu \mathrm{g} / \mathrm{ml} \mathrm{G} 418$ (Roth, Karlsruhe, Germany) to the medium overnight. Subsequently, the cells were washed and treated with $1 \mu \mathrm{M}$ ATRol, ATRal or ATRA for $24 \mathrm{~h}$, or left untreated.

\section{RNA Isolation}

Total RNA was isolated using the RNeasy Mini Kit (Qiagen) according to the manufacturer's instructions, including the oncolumn digestion of DNA with RNase-free DNase I. The RNA was quantified by photometric measurement (NanoDrop Technologies, Wilmington, Del., USA), and its integrity was analyzed on a 2100 bioanalyzer (Agilent Technologies, Palo Alto, Calif., USA).

\section{Quantitative Reverse Transcription Polymerase Chain}

\section{Reaction}

Quantitative reverse transcription polymerase chain reaction was performed as previously described [32]. Purified RNA was reverse transcribed with the SS VILO Mastermix (Life Technologies, Carlsbad, Calif., USA) according to the manufacturer's instructions. TaqMan experiments were carried out on an ABI Prism 7300 sequence detection system (Applied Biosystems, Weiterstadt, Germany) using Assays-on-Demand gene expression products for murine LRAT (Mm00469972_m1) and murine Cyp26a1 (Mm00514486_m1) according to the manufacturer's recommendations. An Assay-on-Demand product for murine GAPDH (Mm99999915_g1) was used as an internal reference to normalize the target transcripts. All measurements were performed in triplicate in separate reaction wells. Experiments were repeated twice.

\section{Cell Viability}

To analyze the influence of retinoids on cellular viability, $1 \times$ $10^{5} \mathrm{~B} 16 \mathrm{~F} 10$ cells were plated in 6-well plates and were treated after $24 \mathrm{~h}$ with $1 \mu \mathrm{M}$ ATRol, ATRal or ATRA, or left untreated. Proliferation and cytotoxicity were assayed using alamarBlue (AbD Serotec, Düsseldorf, Germany) according to the manufacturer's protocol. After $48 \mathrm{~h}, \mathrm{~B} 16 \mathrm{~F} 10$ cells were incubated with $10 \%$ (v/v) alamarBlue reagent for $2 \mathrm{~h}$ at $37^{\circ} \mathrm{C}$, then the absorbance of samples was measured at 560 and $600 \mathrm{~nm}$ with a SpectraMax 250 reader 
Fig. 1. Endogenous expression, overexpression and regulation of LRAT and its induced metabolic transformation of retinol to retinyl esters in the murine melanoma B16F10 cell line. a Taqman analysis of LRAT mRNA expression $24 \mathrm{~h}$ after treatment with $1 \mu \mathrm{M}$ ATRol, ATRal or ATRA in B16F10 cells transfected with LRAT (+LRAT) or control plasmid. Differences between control cells and LRAT+ cells were significant $(\mathrm{p}<0.001)$. b ATRP levels in control and LRAT+ cells after $24 \mathrm{~h}$ incubation with the substrate ATRol $(1 \mu \mathrm{M})$ as determined by LC-MS analysis. All experiments were performed in triplicate and were repeated twice.

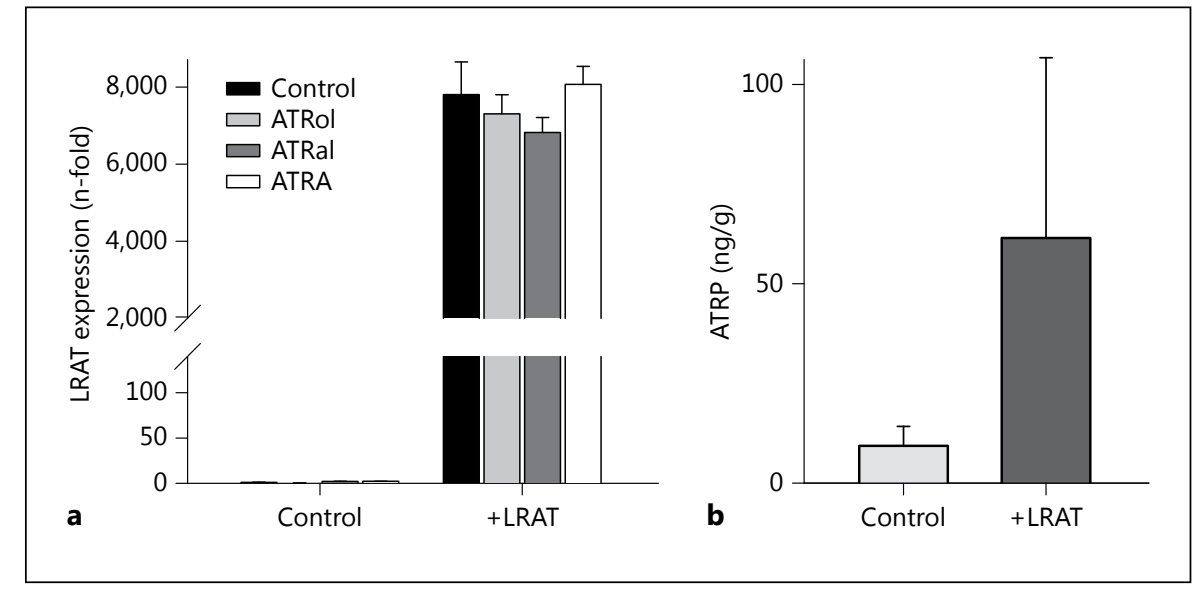

(Molecular Devices, Ismaning, Germany). Data analysis was performed according to the manufacturer's recommendations. Experiments were repeated twice.

\section{Retinoid Analysis}

High-performance liquid chromatography mass spectrometry-mass spectrometry (LC-MS) analyses were performed using a standard protocol of a previously published methodology under dark yellow/amber light [33]. The concentrations of 4-oxo-retinoic acid (4-oxo-RA), ATRol, all-trans-retinyl palmitate (ATRP) and ATRA were determined in the collected cells originating from cell culture in triplicate. Quantification was performed as previously described [33]. In a draft, sample preparation was performed using $100 \mathrm{mg}$ of the sample (if samples were under $100 \mathrm{mg}$, water was added up to the used standard weight: $100 \mathrm{mg}$ ), vortexed for $10 \mathrm{~s}$, put in an ultrasonic bath for $5 \mathrm{~min}$, shaken for $6 \mathrm{~min}$ and centrifuged at $13,000 \mathrm{rpm}$ in a Heraeus Biofuge Fresco at $4^{\circ} \mathrm{C}$. After centrifugation, the supernatants were dried in an Eppendorf concentrator 5301 (Eppendorf, Germany) at $30^{\circ} \mathrm{C}$. The dried extracts were resuspended with $60 \mu \mathrm{l}$ of methanol, diluted with $40 \mu \mathrm{l}$ of a 60 -mM aqueous ammonium acetate solution, transferred to an autosampler and subsequently analyzed.

\section{Statistical Analysis}

Statistical analysis was performed with Sigmaplot version 11 using Student's t test. Data are given as arithmetical means \pm standard error of the mean. Values of $p<0.05, p<0.01$ and $\mathrm{p}<0.001$ were considered significant and are indicated in the figures.

\section{Results}

\section{Endogenous Expression, Overexpression and}

Regulation of LRAT in the Murine Melanoma Cell

Line B16F10

In previous work, we had hypothesized that LRAT expression may be important for reduced ATRol levels in retinoid-resistant human melanoma cell lines [20]. Therefore, we wanted to evaluate the role of LRAT in the retinoid metabolism of the murine retinoid-sensitive cell line B16F10. Interestingly, in contrast to human melanoma cell lines [20], we found that B16F10 cells do not express LRAT mRNA ( $C_{t}$ value 34.4 ; fig. 1a). Next, we generated an LRAT-overexpressing B16F10 cell line by transient mouse LRAT transfection (B16F10 + LRAT). LRAT expression was significantly increased $\left(C_{t}\right.$ value 21.2; $\mathrm{p}<0.001)$ in B16F10 + LRAT cells as compared to B16F10 transfected with the control vector (control cells; fig. 1a). Expression of LRAT did not change after treatment with its substrate ATRol $(1 \mu \mathrm{M})$, ATRal $(1 \mu \mathrm{M})$ or ATRA (1 $\mu$; fig. 1a).

LRAT esterifies ATRol to all-trans-retinyl ester, mainly ATRP [21]. LRAT overexpression was confirmed by quantification of ATRP by sensitive LC-MS measurements. After ATRol incubation ( $1 \mu \mathrm{M}$ for $24 \mathrm{~h})$, higher ATRP mean levels were detected in B16F10 + LRAT cells when compared to control cells according to the higher LRAT expression and higher esterification reaction in the B16F10 + LRAT cells (fig. 1b).

\section{LRAT Overexpression Diminished Responsiveness to Retinoid Treatment}

The antiproliferative effects of retinoids are well established in the murine melanoma cell line B16F10 [23, 26, $27,30,31]$. To determine the effects of LRAT overexpression on retinoid sensitivity, we treated B16F10 control and +LRAT cells with $1 \mu \mathrm{M}$ ATRol, ATRal or ATRA for $48 \mathrm{~h}$ and assessed cellular viability by the alamarBlue assay. Importantly, LRAT overexpression significantly diminished responsiveness to retinoid treatment $(\mathrm{p}=0.026$ for ATRal and $\mathrm{p}<0.001$ for ATRA; fig. 2). 


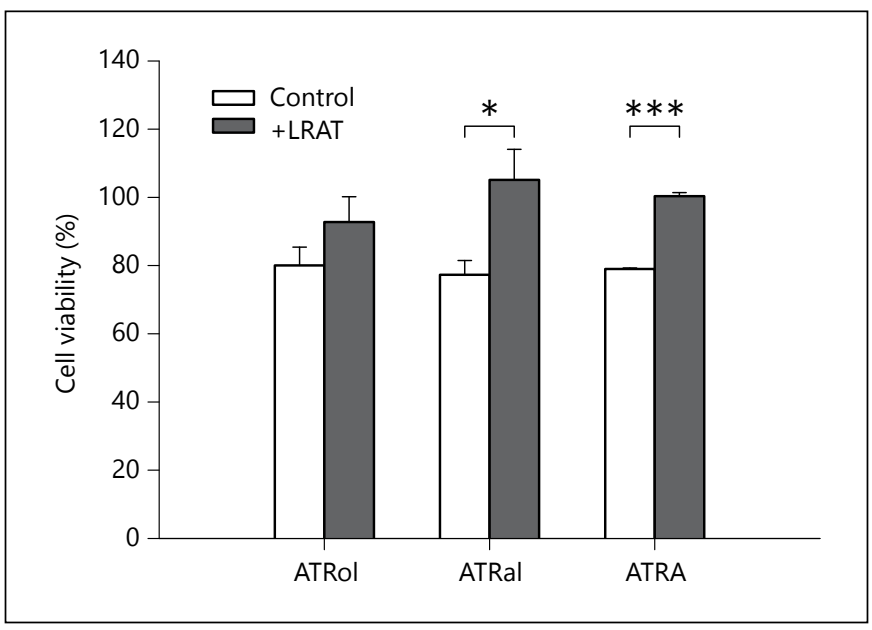

Fig. 2. LRAT overexpression reduces retinoid antitumor efficacy in the murine melanoma B16F10 cell line. Influence of retinoids on cell viability. B16F10 control cells and B16F10 + LRAT cells were treated with $1 \mu \mathrm{M}$ ATRol, ATRal, ATRA or were left untreated for $48 \mathrm{~h}$. Measurements were performed by the alamarBlue assay, and the results were related to the untreated control. ${ }^{*} \mathrm{p}<0.05,{ }^{* * *} \mathrm{p}<0.001$.

\section{Role of LRAT in Retinol Metabolism of Murine Melanoma}

Decreased levels of biologically active retinoids could be the reason for reduced retinoid responsiveness in B16F10 + LRAT cells. Therefore, we determined the ATRA-metabolizing enzyme Cyp26A1 in this study functioning as a molecular marker to monitor the intracellular retinoid status [34-37]. Cyp26a1 mRNA expression was significantly reduced in B16F10 + LRAT cells as compared to control cells (fig. 3). If the observed effect on Cyp26a1 expression is mediated by an LRAT-induced deficiency of biologically active retinoids, the addition of ATRA should rescue the cells. Indeed, 24-hour incubation with ATRA partly re-elevated ('rescued') the expression of Cyp26a1 in B16F10 + LRAT cells (fig. 3). The difference between B16F10 control cells and B16F10 + LRAT cells treated with ATRA was not significant. These results indicate that $\mathrm{B} 16 \mathrm{~F} 10+\mathrm{LRAT}$ cells possess decreased levels of biologically active retinoids.

\section{LRAT Overexpression Diminishes Intracellular Levels} of Biologically Active Retinoids

To gain further insight into the role of LRAT in retinol metabolism, its substrate ATRol and its biologically active metabolite ATRA were determined using LC-MS in B16F10 + LRAT and control cells. The Cyp26a1 product, 4-oxo-RA, which represents a metabolite of ATRA, was also analyzed. Endogenous ATRol remained unchanged

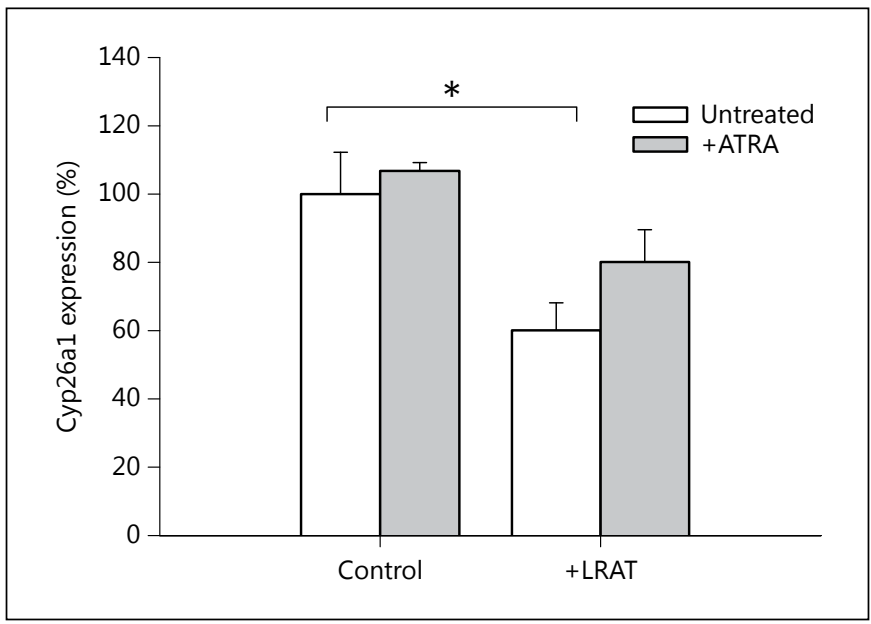

Fig. 3. Overexpression of LRAT reduces expression of Cyp26a1, a retinoid-regulated marker gene used to monitor retinoid signaling. Taqman analysis was performed to measure Cyp26a1 mRNA expression in B16F10 control and B16F10 + LRAT cells and after $24 \mathrm{~h}$ of treatment with $1 \mu \mathrm{M}$ ATRA. ${ }^{*} \mathrm{p}<0.05$.

$(\mathrm{p}=0.636)$, while endogenous levels of ATRA and 4-oxo-RA were under the detection limit in both clones (fig. 4a). Importantly, after ATRol incubation $(1 \mu \mathrm{M}$ for $24 \mathrm{~h}), \mathrm{B} 16 \mathrm{~F} 10+$ LRAT cells showed significantly reduced ATRol levels $(\mathrm{p}=0.005)$, reduced ATRA levels $(\mathrm{p}=0.032)$ and reduced 4-oxo-RA levels $(\mathrm{p}=0.026)$ as compared to the control cells (fig. 4b).

\section{Discussion}

There is an obvious association between vitamin A status, retinoid signaling and cancer development that led to the examination of retinoids as preventive and therapeutic agents for a variety of cancers $[10,11,38]$. Accordingly, the retinol-esterifying enzyme LRAT has been the subject of retinoid and tumor research for many years. Recently, we found that human melanoma possesses high LRAT expression and high esterification potential when compared to human melanocytes [20]. By studying retinoid metabolism in retinoid-responsive murine B16F10 cells, we hoped to discover novel successful strategies to overcome resistance of human melanoma to retinoid treatment.

Studies in LRAT knockout mice revealed that LRAT is the predominant retinol acyltransferase regulating retinol levels [37, 39-41]. To our knowledge, this is the first study presenting evidence that LRAT expression is near- 

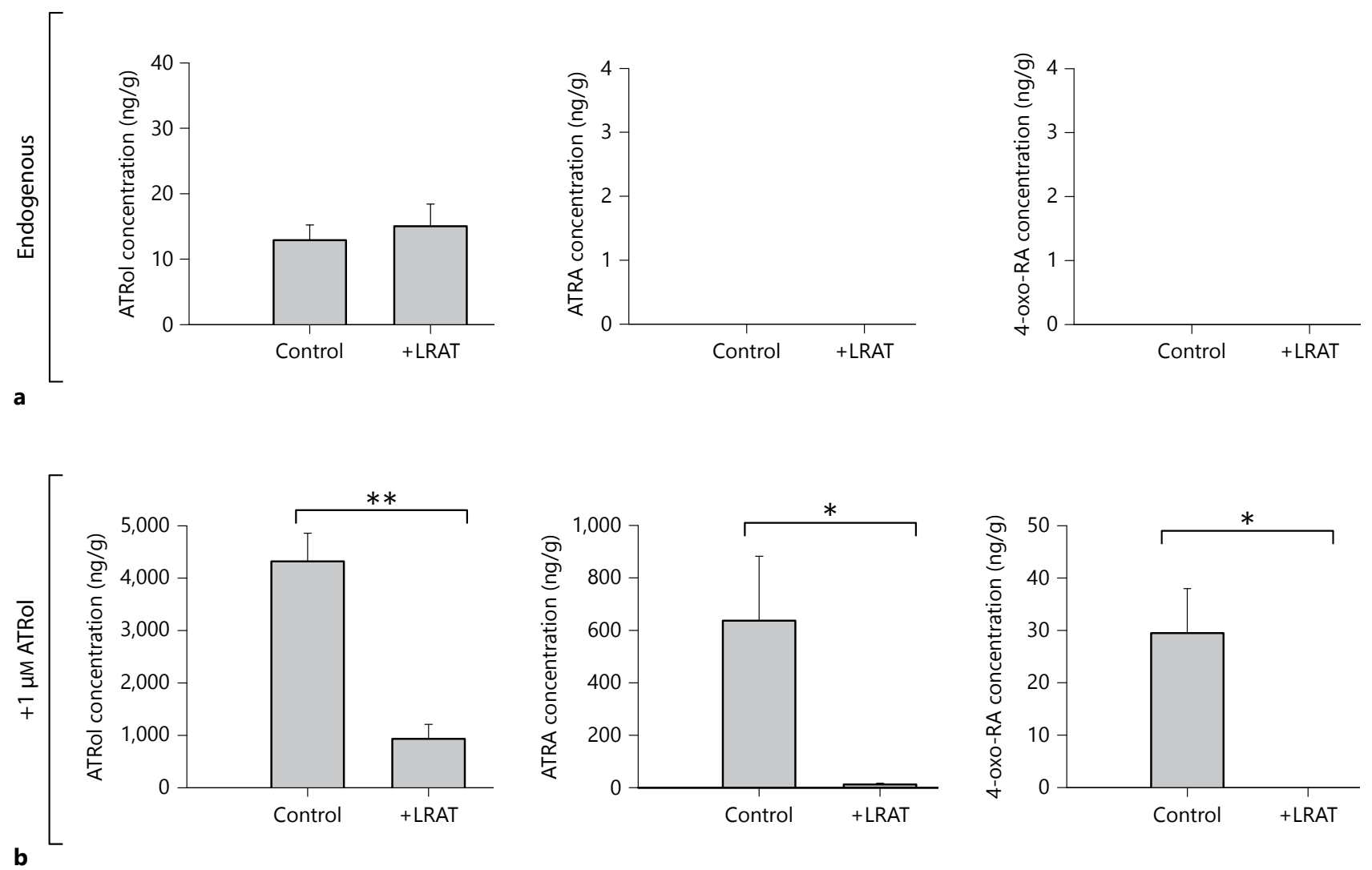

Fig. 4. LRAT overexpression reduces levels of biologically active retinoids in the murine melanoma B16F10 cell line. a Endogenous levels of ATRol, ATRA and 4-oxo-RA in B16F10 melanoma cells were determined by LC-MS analysis. Levels of ATRA and 4-oxo-RA were below the detection limit. b Levels of ATRol, ATRA and 4-oxo-RA $24 \mathrm{~h}$ after incubation with $1 \mu \mathrm{M}$ ATRol. Experiments were performed in triplicate and were repeated twice. ${ }^{*} \mathrm{p}<0.05$, ** $\mathrm{p}<0.01$ : considered as significant. ly absent in the retinoid-sensitive murine melanoma cell line B16F10. Additionally, retinoids did not influence LRAT expression in these murine cells as was previously described in human melanoma cell lines [20].

The growth-inhibitory and prodifferentiating effects of various endogenous and synthetic retinoids are well characterized in murine melanoma cell lines like B16F10 $[23,26,27,30,31]$. For this reason, this cell line was chosen for our experiments. A hallmark of cancer cells is the alteration of metabolic pathways [42]. However, the molecular changes responsible for the biological activity of retinoids in murine melanoma are not well understood. It was shown in B16 melanoma cells that ATRA treatments induce an increase in protein kinase C RNA and protein levels, thus resulting in altered gene transcription via phosphorylation of the transcription factor complex activator protein-1 [30], the activity of which is itself also increased by ATRA in B16 cells [43], and activator pro- tein-1 was assumed to contribute to the final phenotype of growth arrest and differentiation by ATRA [26]. Estler et al. [44] performed microarray analysis and showed that ATRA 'normalized' the expression of genes involved in energy metabolism, DNA replication, DNA repair and differentiation in B16 melanoma cells. Pathway analysis suggested that CDC2, CHEK1, CDC45L and MCM6 are key players in mediating the biological activity of ATRA in B16 melanoma cells [44]. Importantly, we showed that LRAT overexpression decreased these retinoid-induced antiproliferative effects in B16F10 cells in vitro, thus indicating that retinol metabolism is important for the mediation of tumor resistance towards retinoid treatment.

Regulation of retinoid metabolism is complex $[1,5,6]$, and aberrant vitamin A metabolism in cancer cells could represent a potential retinoid resistance mechanism in tumor cells. Accordingly, both the synthesis and metabolism of the bioactive metabolites of ATRol are sometimes 


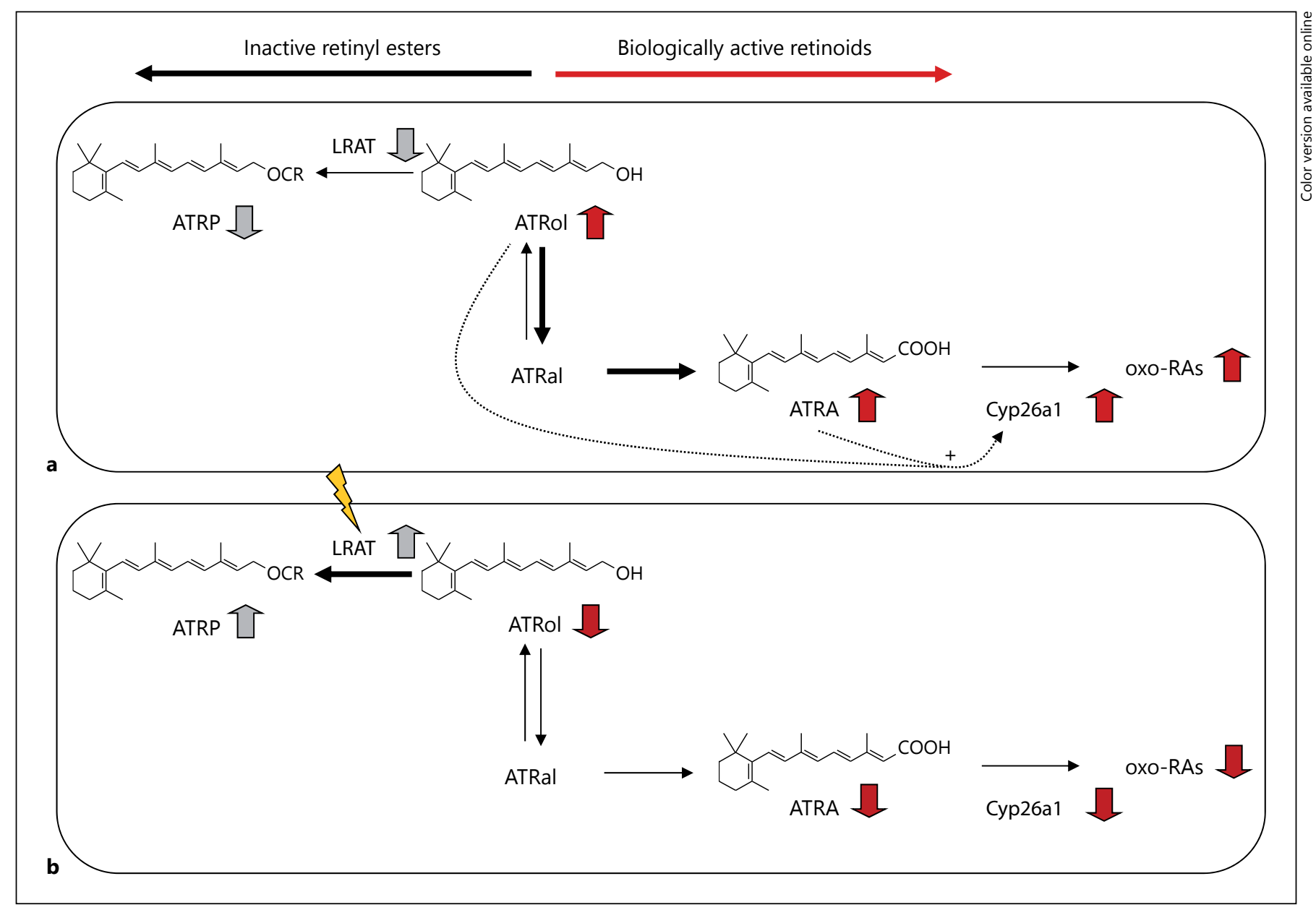

Fig. 5. Direct link between LRAT expression and regulation of biologically active ATRA levels in B16F10 cells (a) and LRAT-overexpressing B16F10 cells (b). Various enzymes, binding proteins and further retinoid derivatives are not illustrated in this schematic. Dotted arrows $(+)$ represent gene upregulation pathways induced by retinoids. impaired in cancer cells $[10,11]$. The major catabolic enzyme known to regulate ATRA levels is Cyp26a1 [34, 45]. It can decrease intracellular levels of ATRA by metabolism to its oxo- and hydroxy-derivatives [46]. For example, in squamous cell carcinoma, Cyp26a1 expression, activity, turnover rate and catabolism of ATRA are increased when compared to normal keratinocytes [47]. Cyp26a1 was also previously described as an autoregulated retinoid target gene [34-37]. Its expression correlates with the tissue retinol level [36], and its expression levels were used to monitor intracellular retinoid levels and retinoid signaling [37]. Previous reports described Cyp26a1 regulation in LRAT knockout mice [37, 48]. Cyp26al expression in different tissues increased in LRAT knockout animals when compared to wild-type animals [48] and correlated with the tissue retinol level in the LRAT knockdown mice [37]. Consistently with low ATRol and ATRA levels in transfected B16F10 + LRAT cells, Cyp26a1 expression was reduced when compared to B16F10 control cells lacking LRAT (fig. 3). If the observed effect on Cyp26a1 expression is mediated by an LRATinduced deficiency of biological active retinoids, the addition of ATRA should diminish this effect. Indeed, in this rescue experiment, we showed that ATRA treatment leads to the upregulation of Cyp26a1 expression in B16F10 + LRAT cells. These results provide evidence that the effects of LRAT overexpression on Cyp26al expression can be decreased after ATRA treatment. The regulation of Cyp26a1 expression in the LRAT-overexpressing B16F10 cells suggests that LRAT also functions as an important regulator of intracellular retinoid concentrations and signaling. 
Another enzyme, the acyl-CoA:diacylglycerol acyltransferase 1, functions as an acyl-CoA:retinol acyltransferase in murine skin [49]. Acyl-CoA:diacylglycerol acyltransferase 1 deficiency resulted in elevated levels of ATRA in the skin and caused enhanced sensitivity to topically administered retinol [49]. This is consistent with our results indicating retinol esterification as an important regulatory mechanism influencing the synthesis of ATRA from its precursor ATRol.

To verify the retinoid signaling effects induced by LRAT overexpression, endogenous retinoids were determined using LC-MS measurements. Endogenous levels of retinoids were comparable in the B16F10 + LRAT cell and its control. However, inactive retinyl ester levels increased, and levels of the substrate ATRol and biologically active ATRA significantly decreased in LRAT-overexpressing B16F10 cells incubated with ATRol.

These results revealed a direct link between LRAT expression and the regulation of ATRA levels (fig. 5). We assume that in the presence of LRAT, ATRol can be efficiently converted to retinyl esters in B16F10 + LRAT cells. Therefore, less ATRol is available for ATRA synthesis and retinoid signaling monitored by the expression of the ATRA-induced Cyp26a1 protein is reduced. Interesting- ly, the ATRA metabolite and product of Cyp26a1, 4-oxoRA, which is normally quickly further metabolized to water-soluble 4-oxo-retinoids, was also shown to possess biological activity in the skin [50]. We found that its levels are also decreased in LRAT-overexpressing melanoma cells.

In conclusion, our results indicate that the absence of retinol esterification led to higher ATRol levels remaining for further metabolism to active ATRA. Therefore, LRAT deficiency is important for mediating retinoid responsiveness in the murine melanoma cells. Our data suggest that LRAT overexpression represents a novel mechanism by which tumor cells can escape ATRA-induced tumorsuppressive RAR signaling.

\section{Acknowledgments}

This work was supported by a START grant (to P.A.) of the Medical Faculty of the RWTH Aachen University.

\section{Disclosure Statement}

The authors have no conflict of interest to declare.

\section{References}

1 Amann PM, Eichmuller SB, Schmidt J, Bazhin $\mathrm{AV}$ : Regulation of gene expression by retinoids. Curr Med Chem 2011;18:1405-1412.

$\checkmark 2$ Lehman PA, Franz TJ: Assessing the bioequivalence of topical retinoid products by pharmacodynamic assay. Skin Pharmacol Physiol 2012;25:269-280.

3 Guy RH: Skin - 'that unfakeable young surface'. Skin Pharmacol Physiol 2013;26:181189.

4 Lademann J, Kocher W, Yu R, Meinke MC, $\mathrm{Na}$ Lee B, Jung S, Sterry W, Darvin ME: Cutaneous carotenoids: the mirror of lifestyle? Skin Pharmacol Physiol 2014;27:201.

5 Blomhoff R, Blomhoff HK: Overview of retinoid metabolism and function. J Neurobiol 2006;66:606-630.

6 Amann PM, Hofmann C, Freudenberger M, Holland-Cunz S, Eichmuller SB, Bazhin AV: Expression and activity of alcohol and aldehyde dehydrogenases in melanoma cells and in melanocytes. J Cell Biochem 2012;113: 792-799.

7 Duester G: Families of retinoid dehydrogenases regulating vitamin a function: Production of visual pigment and retinoic acid. Eur J Biochem 2000;267:4315-4324.

8 Paterson EK, Ho H, Kapadia R, Ganesan AK: 9-cis Retinoic acid is the ALDH1A1 product

LRAT Influences Retinoid Levels and Retinoid Resistance in Murine Melanoma that stimulates melanogenesis. Exp Dermatol 2013;22:202-209.

-9 Baldea I, Costin GE, Shellman Y, Kechris K, Olteanu ED, Filip A, Cosgarea MR, Norris DA, Birlea SA: Biphasic pro-melanogenic and pro-apoptotic effects of all-trans-retinoic acid (ATRA) on human melanocytes: time-course study. J Dermatol Sci 2013;72:168-176.

10 Mongan NP, Gudas LJ: Diverse actions of retinoid receptors in cancer prevention and treatment. Differentiation 2007;75:853-870.

-11 Tang XH, Gudas LJ: Retinoids, retinoic acid receptors, and cancer. Annu Rev Pathol 2011; 6:345-364.

12 Schadendorf D, Worm M, Jurgovsky K, Dippel E, Reichert U, Czarnetzki BM: Effects of various synthetic retinoids on proliferation and immunophenotype of human melanoma cells in vitro. Recent Results Cancer Res 1995; 139: 183-193.

13 Demary K, Wong L, Liou JS, Faller DV, Spanjaard RA: Redox control of retinoic acid receptor activity: a novel mechanism for retinoic acid resistance in melanoma cells. Endocrinology 2001;142:2600-2605.

14 Dhingra K, Papadopoulos N, Lippman S, Lo$\tan$ R, Legha SS: Phase II study of alpha-interferon and 13-cis-retinoic acid in metastatic melanoma. Invest New Drugs 1993;11:39-43.
15 Rosenthal MA, Oratz R: Phase II clinical trial of recombinant alpha $2 \mathrm{~b}$ interferon and 13 cis retinoic acid in patients with metastatic melanoma. Am J Clin Oncol 1998;21:352-354.

16 Sondak VK, Liu PY, Flaherty LE, Fletcher WS, Periman P, Gandara DR, Taylor SA, Balcerzak SP, Meyskens FL Jr: A phase II evaluation of all-trans-retinoic acid plus interferon alfa-2a in stage IV melanoma: a Southwest Oncology Group study. Cancer J Sci Am 1999;5:41-47.

17 Richtig E, Soyer HP, Posch M, Mossbacher U, Bauer P, Teban L, Svolba G, Wolf IH, Fritsch P, Zelger B, Volc-Platzer B, Gebhart W, Mischer P, Steiner A, Pachinger W, Hintner H, Gschnait F, Rappersberger K, Pilarski P, Pehamberger H: Prospective, randomized, multicenter, double-blind placebo-controlled trial comparing adjuvant interferon alfa and isotretinoin with interferon alfa alone in stage IIA and IIB melanoma: European Cooperative Adjuvant Melanoma Treatment Study Group. J Clin Oncol 2005;23:8655-8663.

-18 Passeron T, Valencia JC, Namiki T, Vieira WD, Passeron H, Miyamura Y, Hearing VJ: Upregulation of SOX9 inhibits the growth of human and mouse melanomas and restores their sensitivity to retinoic acid. J Clin Invest 2009;119:954-963. 
19 Pierron A, Le Pape E, Montaudie H, Castela E, De Donatis GM, Allegra M, Bertolotto C, Rocchi S, Cheli Y, Ballotti R, Passeron T: PGJ2 restores RA sensitivity in melanoma cells by decreasing PRAME and EZH2. J Dermatol Sci 2014;73:258-261.

20 Amann PM, Luo C, Owen RW, Hofmann C, Freudenberger M, SchadendorfD, Eichmuller SB, Bazhin AV: Vitamin A metabolism in benign and malignant melanocytic skin cells: importance of lecithin/retinol acyltransferase and RPE65. J Cell Physiol 2012;227:718-728.

-21 Barry RJ, Canada FJ, Rando RR: Solubilization and partial purification of retinyl ester synthetase and retinoid isomerase from bovine ocular pigment epithelium. J Biol Chem 1989;264:9231-9238.

22 Levine N: Effects of topical retinoic acid on intracutaneously implanted S91 melanoma in mice. J Invest Dermatol 1985;85:89-92.

-23 Jiang CG, Taylor DD, Black PH: Effect of retinoic acid on tumor-mediated immunologic alterations in mice bearing a variant of the B16 melanoma. Int J Cancer 1990;46:10541058.

-24 Spanjaard RA, Ikeda M, Lee PJ, Charpentier B, Chin WW, Eberlein TJ: Specific activation of retinoic acid receptors (RARs) and retinoid $\mathrm{X}$ receptors reveals a unique role for RARgamma in induction of differentiation and apoptosis of S91 melanoma cells. J Biol Chem 1997;272:18990-18999.

25 Sengupta S, Ray S, Chattopadhyay N, Biswas $\mathrm{N}$, Chatterjee A: Effect of retinoic acid on integrin receptors of B16F10 melanoma cells. J Exp Clin Cancer Res 2000;19:81-87.

26 Niles RM: Vitamin A (retinoids) regulation of mouse melanoma growth and differentiation. J Nutr 2003; 133:282S-286S.

27 Liu X, Chan SY, Ho PC: Comparison of the in vitro and in vivo effects of retinoids either alone or in combination with cisplatin and 5 -fluorouracil on tumor development and metastasis of melanoma. Cancer Chemother Pharmacol 2008;63:167-174.

-28 Weinzweig J, Tattini C, Lynch S, Zienowicz R, Weinzweig N, Spangenberger A, Edstrom L: Investigation of the growth and metastasis of malignant melanoma in a murine model: The role of supplemental vitamin A. Plast Reconstr Surg 2003;112:152-158, discussion 159161.

29 Zhao X, Graves C, Ames SJ, Fisher DE, Spanjaard RA: Mechanism of regulation and suppression of melanoma invasiveness by novel retinoic acid receptor-gamma target gene carbohydrate sulfotransferase 10 . Cancer Res 2009;69:5218-5225.
30 Huang Y, Boskovic G, Niles RM: Retinoic acid-induced AP-1 transcriptional activity regulates B16 mouse melanoma growth inhibition and differentiation. J Cell Physiol 2003; 194:162-170.

-31 Guruvayoorappan C, Pradeep CR, Kuttan G: 13-cis-Retinoic acid induces apoptosis by modulating caspase- $3, \mathrm{Bcl}-2$, and p53 gene expression and regulates the activation of transcription factors in B16F-10 melanoma cells. J Environ Pathol Toxicol Oncol 2008;27: 197-207.

32 Heise R, Skazik C, Marquardt Y, Czaja K, Sebastian K, Kurschat P, Gan L, Denecke B, Ekanayake-Bohlig S, Wilhelm KP, Merk HF, Baron JM: Dexpanthenol modulates gene expression in skin wound healing in vivo. Skin Pharmacol Physiol 2012;25:241-248.

33 Ruhl R: Method to determine 4-oxo-retinoic acids, retinoic acids and retinol in serum and cell extracts by liquid chromatography/diodearray detection atmospheric pressure chemical ionisation tandem mass spectrometry. Rapid Commun Mass Spectrom 2006;20: 2497-2504.

34 White JA, Beckett-Jones B, Guo YD, Dilworth FJ, Bonasoro J, Jones G, Petkovich M: cDNA cloning of human retinoic acid-metabolizing enzyme (hP450RAI) identifies a novel family of cytochromes p450. J Biol Chem 1997;272: 18538-18541.

35 Abu-Abed SS, Beckett BR, Chiba H, Chithalen JV, Jones G, Metzger D, Chambon P, Petkovich M: Mouse P450RAI (Cyp26) expression and retinoic acid-inducible retinoic acid metabolism in F9 cells are regulated by retinoic acid receptor gamma and retinoid $\mathrm{X}$ receptor alpha. J Biol Chem 1998;273:24092415.

36 Yamamoto Y, Zolfaghari R, Ross AC: Regulation of Cyp26 (cytochrome P450RAI) mRNA expression and retinoic acid metabolism by retinoids and dietary vitamin $\mathrm{A}$ in liver of mice and rats. FASEB J 2000;14:2119-2127.

37 Liu L, Gudas LJ: Disruption of the lecithin: retinol acyltransferase gene makes mice more susceptible to vitamin A deficiency. J Biol Chem 2005;280:40226-40234.

38 Niles RM: Biomarker and animal models for assessment of retinoid efficacy in cancer chemoprevention. Acta Pharmacol Sin 2007;28: 1383-1391.

39 Batten ML, Imanishi Y, Maeda T, Tu DC, Moise AR, Bronson D, Possin D, Van Gelder RN, Baehr W, Palczewski K: Lecithin-retinol acyltransferase is essential for accumulation of all-trans-retinyl esters in the eye and in the liver. J Biol Chem 2004;279:10422-10432.
40 O’Byrne SM, Wongsiriroj N, Libien J, Vogel S, Goldberg IJ, Baehr W, Palczewski K, Blaner WS: Retinoid absorption and storage is impaired in mice lacking lecithin: Retinol acyltransferase (LRAT). J Biol Chem 2005;280: 35647-35657.

41 Wongsiriroj N, Piantedosi R, Palczewski K, Goldberg IJ, Johnston TP, Li E, Blaner WS: The molecular basis of retinoid absorption: a genetic dissection. J Biol Chem 2008;283: 13510-13519.

42 Warburg O, Wind F, Negelein E: The metabolism of tumors in the body. J Gen Physiol 1927;8:519-530.

43 Desai SH, Niles RM: Characterization of retinoic acid-induced AP-1 activity in B16 mouse melanoma cells. J Biol Chem 1997;272: 12809-12815.

44 Estler M, Boskovic G, Denvir J, Miles S, Primerano DA, Niles RM: Global analysis of gene expression changes during retinoic acid-induced growth arrest and differentiation of melanoma: comparison to differentially expressed genes in melanocytes vs melanoma. BMC Genomics 2008;9:478.

45 Baert B, De Spiegeleer B: Local skin pharmacokinetics of talarozole, a new retinoic acid metabolism-blocking agent. Skin Pharmacol Physiol 2011;24:151-159.

46 Heise R, Mey J, Neis MM, Marquardt Y, Joussen S, Ott H, Wiederholt T, Kurschat P, Megahed M, Bickers DR, Merk HF, Baron JM: Skin retinoid concentrations are modulated by $\mathrm{Cy}$ p26AI expression restricted to basal keratinocytes in normal human skin and differentiated 3D skin models. J Invest Dermatol 2006; 126:2473-2480.

47 Klaassen I, Brakenhoff RH, Smeets SJ, Snow GB, Braakhuis BJ: Enhanced turnover of alltrans-retinoic acid and increased formation of polar metabolites in head and neck squamous cell carcinoma lines compared with normal oral keratinocytes. Clin Cancer Res 2001;7:1017-1025.

48 Liu L, Tang XH, Gudas LJ: Homeostasis of retinol in lecithin: Retinol acyltransferase gene knockout mice fed a high retinol diet. Biochem Pharmacol 2008;75:2316-2324.

49 Shih MY, Kane MA, Zhou P, Yen CL, Streeper RS, Napoli JL, Farese RV Jr: Retinol esterification by DGAT1 is essential for retinoid homeostasis in murine skin. J Biol Chem 2009;284:4292-4299.

50 Baron JM, Heise R, Blaner WS, Neis M, Joussen S, Dreuw A, Marquardt Y, Saurat JH, Merk HF, Bickers DR, Jugert FK: Retinoic acid and its 4-oxo metabolites are functionally active in human skin cells in vitro. J Invest Dermatol 2005;125:143-153. 